Illinois State University

ISU ReD: Research and eData

Theses and Dissertations

7-13-2021

\title{
Differences in Mother's Use of Spatial Language With Male and Female Infants During a Block Play Scenario
}

Elizabeth Phillis

Illinois State University, es.phillis@gmail.com

Follow this and additional works at: https://ir.library.illinoisstate.edu/etd

\section{Recommended Citation}

Phillis, Elizabeth, "Differences in Mother's Use of Spatial Language With Male and Female Infants During a Block Play Scenario" (2021). Theses and Dissertations. 1463.

https://ir.library.illinoisstate.edu/etd/1463

This Thesis is brought to you for free and open access by ISU ReD: Research and eData. It has been accepted for inclusion in Theses and Dissertations by an authorized administrator of ISU ReD: Research and eData. For more information, please contact ISUReD@ilstu.edu. 


\section{DIFFERENCES IN MOTHER'S USE OF SPATIAL LANGUAGE WITH MALE AND FEMALE INFANTS DURING A BLOCK PLAY SCENARIO}

\section{ELIZABETH PHILLIS}

\section{Pages}

Construction and language acquisition develop simultaneously, each skill contributing to the development of the other skill (Marcinowski \& Campbell, 2017). The present study was conducted to examine the factors that may contribute to the simultaneous development of construction and language. An investigation was proposed and defended to examine whether caretakers use biased language when directing speech towards male and female infants. Specifically, the study is designed to determine if mothers exhibit biases in their language during a block play scenario. This study addresses whether mothers use more prepositional words or phrases with male or female children. It is expected that mothers will say more spatial prepositions when their infant is a male versus a female. Mothers were given a standard set of block toys and were asked to play for five minutes with their infant in a semi-structured setting. A mixed repeated measures ANOVA was employed to compare the average frequency of spatial prepositions during play sessions with males compared to play sessions with females. One limitation is that this sample only examines mothers. A different outcome might be observed with interactions between fathers and infants. The study will expand the literature by providing information about mothers' behavior and language used when engaging with infants during a time when infants' rate of language development is expanding rapidly.

KEYWORDS: Language, block play, prepositional phrases, mother/child dyad 
DIFFERENCES IN MOTHER'S USE OF SPATIAL LANGUAGE WITH MALE AND

FEMALE INFANTS DURING A BLOCK PLAY SCENARIO

ELIZABETH PHILLIS

A Thesis Submitted in Partial

Fulfillment of the Requirements

for the Degree of

MASTER OF SCEINCE

Department of Psychology

ILLINOIS STATE UNIVERSITY

2021 
(C) 2021 Elizabeth Phillis 
DIFFERENCES IN MOTHER'S USE OF SPATIAL LANGUAGE WITH MALE AND FEMALE INFANTS DURING A BLOCK PLAY SCENARIO

\author{
ELIZABETH PHILLIS
}

COMMITTEE MEMBERS:

Julie M. Campbell, Chair

J. Cooper Cutting 


\section{CONTENTS}

Page

CHAPTER I: INTRODUCTION 1

CHAPTER II: REVIEW OF LITERATURE 3

Why is it Important to Examine Play and Language Development? 3

Do Infants and Children Comprehend Spatial Language? $\quad 5$

Do Mothers Use Language Differently with Male and Female Children? 9

CHAPTER III: METHOD 13

$\begin{array}{ll}\text { Participants } & 14\end{array}$

$\begin{array}{ll}\text { Procedure } & 14\end{array}$

$\begin{array}{ll}\text { Transcription } & 15\end{array}$

$\begin{array}{ll}\text { CHAPTER IV: RESULTS } & 17\end{array}$

$\begin{array}{ll}\text { CHAPTER V: DISCUSSION } & 21\end{array}$

$\begin{array}{ll}\text { Limitations } & 22\end{array}$

$\begin{array}{ll}\text { Future Directions } & 23\end{array}$

REFERENCES 24

APPENDIX A: PHOTOGRAPH OF BLOCKS USED 26

APPENDIX B: COMPLETE TABLE OF SPATIAL WORDS USED FOR CODING 27 


\section{CHAPTER I: INTRODUCTION}

The purpose of this research study is to add to the existing literature on language acquisition that occurs during play scenarios for infants. This study focuses on prepositional and spatial language that occurs during block play. For the purposes of the present study, only the language that comes from mothers will be considered, as the infants were not of speaking age at the time of data collection. This study is a natural continuation of the Marcinowski and Campbell (2017) research, in which a dyadic block play interaction was analyzed. In their study, infants were observed while manipulating objects. The number of objects that were constructed into a cohesive structure were coded (A photograph of the blocks that were used in the study can be found in Appendix A.) Subsequently, an assessment of infants' spatial preposition knowledge was conducted. Infants who showed more skill at constructing with objects had higher scores on the assessment of spatial prepositions. The researchers noted in their discussion that the need to understand the role that language has in the relation between object manipulation and knowledge of spatial prepositions is necessary for a deeper understanding of the development of infant's and children's acquisition of language. This study aims to address the role of parent language on the development of infants' language knowledge by examining play interactions between mothers and infants in which blocks are introduced as a medium for manipulation.

A variable that was not considered in Marcinowski and Campbell's (2017) original research was gender of the infant. In other words, the study did not address whether male or female infants showed increased skills at constructing objects and whether they subsequently had a greater understanding of spatial prepositions. One factor that may influence a difference in developmental acquisition of construction and knowledge of spatial prepositions is the influence of parent language. Does mother language, specifically, the use of spatial prepositions, change 
across time? Do mothers use spatial prepositions differently for male or female infants? Those research questions were addressed in this study using a longitudinal research design. Mothers and infants were observed during six separate semi-structured play scenarios in which a set of building blocks were provided, and mothers were asked to play with their infant for $5 \mathrm{~min}$. Finally, this study examined whether the number of total words said during the play scenario changes across time and if that change differs between male and female children.

A brief explanation of the past research to support the present study will be explored. Second, a description of the procedure used to answer the research questions will be presented. 


\section{CHAPTER II: REVIEW OF LITERATURE}

\section{Why is it Important to Examine Play and Language Development?}

As Marcinowski and Campbell (2017) note, object manipulation and language

acquisition develop simultaneously, each skill contributing to the development of the other skill.

Why is it important to examine play with block toys, as exemplified in the present study?

Greenfield (1991) notes that blocks promote spatial language and language development as a

whole, perpetuating the importance to understand if and when discrepancies in frequency occur. Greenfield (1991) found that before 2 years of age, the Broca's area in the brain is unable to differentiate between sounds and object manipulation, so these skills develop at the same time. After the age of 2, the Broca's area is able to differentiate, so the language and manipulation skills develop separately.

While Greenfield (1991) demonstrated that playing with blocks promote and encourage the use of spatial language, other studies have demonstrated an effect on language when the play scenario is manipulated in some way. In experiments where mothers are given instructional tools on how to engage with their infant during a play scenario, an increase in language acquisition (Christakis et al., 2007) and maternal use of spatial language (Borriello \& Liben, 2018; Ferrara et al., 2011) occurred. Specifically, Christakis et al. (2007) examined whether block play promoted language development through play in 175 families with children aged 1.5 -2.5 years of age. The study consisted of two conditions: in one condition, parents received a set of blocks and a newsletter with different activities and figures to build with their child; in the second, control condition, parents of infants only received blocks and no newsletter was included. The results of their analysis show that the intervention group, who received instructions and activities, showed an increase in language acquisition. Based on those results, it 
can be inferred that the addition of materials in the form of written language, which are then read aloud to children, aid in the increase of language skills and the use of spatial words.

Similar to those results found in Christakis et al. (2007), Borriello and Liben (2018) utilized booklets in their intervention group to compare outcomes with a control group who did not receive booklets. Mothers in the intervention group of their study were provided an information booklet on the importance of spatial language along with objects that afford construction actions. These booklets included information such as: definitions of spatial thinking, how it is important for daily activities, subjects in school, and future jobs, as well as how to encourage this interaction with their child. The researchers hypothesized that giving mothers information on spatial language would increase the spatial guidance they would give to their children during block play. A total of 41 mother and preschool-aged child dyads participated in either an experimental group (caregiver given information on spatial language using the booklet) or the control group who did not receive the information. All 41 dyads were first given a 150-piece LEGO creation, with which they were able to use during free play for 5 $\min$ in a laboratory setting. When the 5 min of free play were up, all the dyads in the experimental group were given an instruction booklet which contained instructions on how to create the structure. The researchers found that the mothers in the experimental group (the dyads that received the booklet on the importance of spatial language) said more spatial words/phrases to their infant than the control group. The findings suggest that when caregivers are given information on the importance of spatial language, they take that information and utilize it immediately, which then affects how they interact with their children.

Lastly, Ferrara et al. (2011) noted that block play scenarios are common play interactions in which spatial language may naturally occur between infants and parents. The researchers 
conducted a study in which the relation between language and play type were examined. Their study included three groups to which the play dyads were randomly assigned: free block play, guided block play, or preassembled block play. Free play referred to the parent/child dyad playing with blocks and being given no specific instructions. Guided play referred to when the parent/child dyad were given a 5-step instruction booklet to use to build (similar to Borriello \& Liben, 2018). Preassembled play referred to when the parent/child dyads played with no specific instruction with a previously completed block figure. By including three different block groups, the researchers were able to address whether free play, guided play, or preassembled block play were more likely to influence the use of spatial language usage exhibited by children and parents

during joint play sessions. The researchers conducted a repeated measures ANOVA and found a significant effect for conditions, meaning the amount of spatial words differed significantly depending on which play group the dyad was placed. It was discovered that guided play produced the most spatial language from both parents and children, while free play brought about the least.

Taken together, the Christakis et al. (2007), the Borriello and Liben (2018), and the Ferrara et al. (2011) studies indicate that language usage differed depending on whether information or instructions were provided to the parent, which promoted the parent's usage of spatial language. In each study, it was concluded that the experimental groups who received written information or instructions displayed an increase use of language while engaged in the play task with their children.

\section{Do Infants and Children Comprehend Spatial Language?}

Greenfield (1991) states that spatial language is important to understand when constructing sentences, as prepositions are a staple in the English language. Research has been 
conducted to determine whether and to what extent children and infants understand spatial language.

One study which embarked on this task of improving our knowledge of what young children understand about spatial language was conducted by Meints et al. (2002). Meints et al. examined specific words to determine which spatial words are understood at young ages. They hypothesized that 'on' and 'under' would be some of the earliest spatial words understood. The procedure included auditory and visual stimuli: the auditory stimulus involved a voice prompting the child to look at an object either on or under the table, and the visual stimulus included animals (a dog, cat, duck, and rabbit) and objects (a cup, bottle, ball, and shoe). The auditory voice would say "Look at [the animal/object] [on/under] the table." On the computer screen in front of them, the infant would see, for example, a dog under the table; this would be a 'typical' situation. An 'atypical' situation would be the dog on the table, as this is not a common or typical place for dogs to be. The same was done for a cup. A cup is typically on a table, not under a table. The results indicated that, when shown animate objects, the children in different age groups responded differently depending on the typicality of the situation (such as, a dog sitting "under" the table, as opposed to the dog sitting "on" the table). The youngest group (the 15-month-olds) associated the stated preposition only with typical situations, the two older groups (the 18- and 24-month-olds) were able to associate the stated preposition with both typical and atypical situations. In other words, when a situation was presented which was not unusual (a dog sitting under a table), the youngest group as well as the older groups were both able to understand the meaning of the spatial preposition utilized. The researchers were able to determine this using eye-tracking technology. When an unusual situation was presented (a dog sitting on a table), the youngest group was unable to demonstrate that they understood the 
meaning of the spatial preposition, as they did not have looking times as long as the older group of infatns. The overall finding was that there are some spatial prepositions that infants understand earlier, in this case, "on" and "under," than other spatial prepositions.

While Meints et al. (2002) examined spatial prepositions used in typical and atypical situations and found that young children understood the meaning more clearly when used in typical situations, other researchers have compared typical words to nonsense words. Casasola and Wilbourn (2004) conducted research on words that do not exist in the English language to determine if infants could still understand the meaning after a habituation period. A total of 32 14-month-old infants were tested using a habituation procedure called "switch design": infants were habituated with a non-word (teek) when viewing a containment event (Big Bird placed in a box). The infants would hear the researcher say "She's putting Big Bird teek the box," while the researcher performed the action of putting Big Bird in the box. On other habituation trials, a second non-word (blick) was used. Blick was used when viewing a supportive event (Big Bird being placed on the box). The infants would hear the researcher say "She's putting Big Bird blick the box," while the researcher placed Big Bird on the box. If infants habituated to the learned association, then they should look longer at the switch trial (in this case, it would be the novel word teek meaning support instead of containment). An ANOVA revealed that infants looked significantly longer at "switch" trials (when teek and blick were switched from their original usage as either containment or support words). Infants in the study were able to associate nonsense words with specific actions, suggesting the route to learning new words may not be specific to what words are used, but rather that a word is consistently applied to the same action repeatedly. 
This finding, that using a word consistently may be the mechanism by which young infants are learning the meaning of words, is important to emphasize in light of the current research and methodology. Here, it is intended to examine the consistency with which mothers use spatial prepositions. By examining this consistency, and whether they are used increasingly over time, this information will be able to be used later to examine whether those infants who heard these words with increased frequency are better able to understand and use those same words later. In other words, similar to Casasola and Wilbourn's (2004) findings that consistency is important for learning word meaning, our study will determine whether consistency in spatial prepositions exists and if that consistency is stable or changing over time.

While Meints et al. (2002) and Casasola and Wilbourn (2004) determined that male infants hear more spatial language as compared to female infants, Kaushanskaya et al. (2013) found language differences in favor of female children, using the Declarative/Procedural theoretical framework model founded by Ullman et al (2002). The researchers hypothesized that female children would outperform male children as well. The researchers recruited 5-7 year old children (69 total, 30 female) to address their research question. The participants were presented with both familiar and unfamiliar material. The familiar materials were nonword stimuli selected from a database due to the similarity to English words. The unfamiliar materials were nonword stimuli that have no similarity to English words. All materials were first shown to participants in a lab setting using a computer that matched familiar words with animals and unfamiliar words with aliens in this teaching phase. The second phase of the study was the testing phase that occurred immediately after the teaching phase, wherein the participants had to match both familiar and unfamiliar words with their respective picture (an animal or an alien) and the participants were timed. The researchers determined that female participants outperformed 
males on word-learning tasks that involved learning familiar material. Along with this finding, the researchers report that females appear to have a stronger ability in regard to phonological and semantic (speech sound and speech meaning, respectively) familiarity effects as compared to males. It can be inferred from the results of this study that female children perform better at language acquisition tasks. If females perform better at language tasks, one fact that may be important to consider in any language acquisition study which considers gender are the results of Kaushanskaya et al. (2013) which demonstrate that female children may acquire language faster than male children. However, the focus of the present study is on the frequency of words said by mothers, and not the rate by which their infants/children subsequently produce words.

Taken together, the Meints et al. (2002), Casasola and Wilbourn (2004), and

Kaushanskaya et al. (2013) studies indicate that infants and children comprehend spatial words, even if the words are not naturally occurring in language. Meints et al. (2002) found that the words "on" and "under" were understood by infants as young as 15 months. Casasola and Wilbourn (2004) found that consistency is key in the understanding of spatial language. Kaushanskaya et al. (2013), conversely, found that female child participants outperformed male child participants on familiar and unfamiliar non-words.

\section{Do Mothers Use Language Differently with Male and Female Children?}

There is research to suggest that, in many instances, mothers use different words, or use words at a higher frequency, with male and female children. Specifically, Pruden and Levine (2017) conducted a study in which they analyzed "what" spatial language during a play scenario. The "what" spatial language was broken up into three categories: shape terms (e.g., circle, triangle), dimension terms (big, little, tall, long), and spatial-feature terms (more 2- or 3dimensional words, like bent, edge, line). A longitudinal design was conducted in which infants 
were observed from 14 months to 46 months during nine separate 90 -minute sessions. No specific instructions were given to the parents; the parents were only asked by the researchers to play naturally with what toys they already owned in their homes. The researchers were curious as to whether parents use more of these "what" words with their male children as compared to female children. Results indicate that parents produced significantly more "what" language when playing with their male children as compared to female children. An analysis was performed to examine whether the amount of spatial language used by parents increased or decreased the amount of spatial language used by male and female children. The results show that parents' production of "what" spatial language fully mediated the gender differences in children's production of the "what" spatial language. These results support the theory that how parents use language affects their children's language use.

As Pruden and Levine (2017) studied differences in "What" spatial language, Clearfield and Nelson (2006) studied biases in conversational language in the household between mothers and their children at the ages 6,9 , and 14 months. The researchers recruited three groups of mother/children dyads: twelve 6-, 9-, and 14-month-olds (six boys and six girls in each age group). Based on past studies, the researchers hypothesized that mothers would speak to and play with their male and female children differently while using gender-neutral toys. The researchers coded for mothers' verbal behavior. The researchers' results indicate that mothers said more attentional statements to male children across the ages. An example of an attentional statement would be the mother saying "Look, [child name]!" to direct their infant's attention to that with which they were playing. A MANOVA found that mothers made more comments (which provide the infant with information on what they are looking at or what they are doing) to male children than female children, while making more interpretations (statements of needs, 
wishes, or feelings of the infant) to female children than male children. These results indicate that, with children of both genders as young as 6 months of age, mothers play and speak to their male and female children differently. These results from Clearfield and Nelson (2006) support that a conversational and word choice bias exists from mothers to their male and female infants.

The previous studies demonstrate a difference in word frequency usage from mothers to male and female infants. Still more evidence can be found that parents use language differently between male and female children. Crowley et al. (2001) examined recorded conversations from museums between parents and their children at different exhibits. Even though there were not blocks or play time conversations analyzed, it is important to note gender differences in language usage across common parent/child dyadic situations. The researchers studied whether parents use more language with their male children in a museum setting than with their female children in the same setting. The researchers coded three different types of interactions parents had with their children. These were: conversations with explanations, conversations with giving directions, and conversations talking about evidence. A total of 298 families participated in the study and the children's ages ranged from 1-8 years. The conversations were coded for just father interactions, just mother interactions, and both parent interactions. It was found that both mothers and fathers explained more to their male children than to their female children. These findings, similar to Pruden and Levine (2017) and Clearfield and Nelson (2006), support the idea that parents do use language differently according to whether they are engaged in conversation with male and female children.

The findings of the studies described above, in which males were more likely to receive significantly more "what" words (Pruden \& Levine, 2017), were more likely to receive more comments (Clearfield \& Nelson, 2006), and were more likely to be spoken to by their parent 
(Crowley et al., 2001), indicating that parents do use language differently with male and female children in both play and non-play settings.

The present study aims to fill in some of the gaps from the research described above, and to continue the work Marcinowski and Campbell (2017) started. To do so, four research questions will be considered. First, do mothers use more spatial language with their male children over female children? In addition to this, do the number of spatial prepositions that mothers say to their infants increase over time depending on the gender of the infant? Third, do the number of total words said during play differ between male children and female children? Finally, do the total number of words said to the infant participants increase over time? 


\section{CHAPTER III: METHOD}

The focus of the present study was to add not only to the existing research of language acquisition during play scenarios, but to act as a natural continuation of the Marcinowski and Campbell (2017) research, due to their finding that object (i.e.: toy blocks) construction is connected to spatial language acquisition for infants.

There are four research questions and hypotheses that were considered. First, do mothers use more spatial language with their male children over female children? It is hypothesized that mothers will use more spatial language with their male children over female children. This hypothesis is based on the research described above, but particularly the Pruden and Levine (2017) and Clearfield and Nelson (2006) studies that indicate mothers use language differently with their male and female children. This hypothesis will be tested using a mixed repeated measures ANOVA.

Second, do the number of spatial prepositions that mothers say to their infants increase over time depending on the gender of the infant? It is hypothesized that mothers will gradually say more spatial prepositions to male children over female children. This hypothesis will be tested using a mixed repeated measures ANOVA.

Third, do the number of total words said during play differ between male children and female children? It is hypothesized that mothers will say more total words to male children over female children. This hypothesis will be tested using a mixed repeated measures ANOVA.

Lastly, do the total number of words said to the infant participants increase over time? It is hypothesized that mothers will gradually increase the amount of total words said as the infants age. This hypothesis will be tested using a repeated measures ANOVA. 


\section{Participants}

A total of 37 infant/mother dyads were recruited to participate in a larger study conducted by Drs. Emily Marcinowski and Julie Campbell at Virginia Commonwealth University and Illinois State University, respectively. Of the 37 infant participants, 20 were female. The average starting age of the infant was 5 months. There was not a set starting age for the infants, as their start was not determined by age, but by an assessment of trunk stability. Once truck stability was determined, the play observation began. The dyad was able to have its first recorded play interaction (the baseline) when the infant would sit upright without the aid of their mother or another object. Of the 37 mothers, $8.1 \%$ stated their child is of Hispanic/Latino ethnicity. Education level of the mothers was recorded as well: 5.4\% received some high school or less; $5.4 \%$ received a high school diploma; $8.1 \%$ have some college or trade education; $18.9 \%$ were college graduates; and $62.2 \%$ of the mothers received a postgraduate degree. Lastly, income was reported: $10.8 \%$ (4 mothers) reported $\$ 0-\$ 15,000 ; 5.4 \%$ reported $\$ 15,000-\$ 24,999$; $2.7 \%$ reported $\$ 35,000-\$ 44,999 ; 5.4 \%$ reported $\$ 45,000-\$ 59,999 ; 13.5 \%$ reported $\$ 60,000$ $\$ 79,999$; and $59.5 \%$ reported income exceeding $\$ 80,000$. One dyad was discarded during analysis due to the fact that only one play meeting was recorded.

\section{Procedure}

The infant/mother dyads were recorded on five occasions. First, a baseline play scenario was recorded. Again, the baseline scenario was recorded when the infant could sit upright without aid. After the baseline play scenario, the dyads were observed at 3 weeks post-baseline, 1.5 months post-baseline, 6 months post-baseline, and 12 months post-baseline. Each play scenario lasted $5 \mathrm{~min}$, and the same toy blocks were used. 
When the mother and her infant arrived, the dyad was given a bag of block toys and were asked by the researcher to interact with their infant for five minutes and that they would be notified when the five minutes were up. To avoid any priming or bias, the researcher did not mention play or conversation, just that there were five minutes available. Following these brief instructions and handing the bag of blocks to the parent, the timer began. A common observation may include an interaction in which the mother showed the infant how to put the blocks together and how to stack them. Another common interaction included mothers waving the blocks in front of the infant's face to bring their attention back to the play scenario. If the child was being fussy or became upset, the timer was paused and the play scenario ended. If the infant calmed enough to continue the play scenario, time began again until the five minutes of observation had passed.

\section{Transcription}

A team of undergraduate and graduate research assistants transcribed the recorded audio from the videos. The team first transcribed all conversations from the mother by typing into a Microsoft Word document all the word and sounds that were heard during the five minute observation. The videos were viewed using VLC Media Player. If words said in the video could not be determined, the coders used dash marks, “_,, to indicate that the words were unintelligible. However, every effort was made to add a dash for separate unintelligible words. For example, if a research assistant heard "looo at the monnsss", this would be transcribed as “__ at the __ so that four words were tallied in the final word count. If the mother was making the sound of an animal, for example a snort or grunt for a pig, the coder will type "[sound]," but if the mother says, "A pig says 'oink.,", then the coder will spell out the word "oink." Both the sounds and words were included in the final word count of the play scenario. 
Reliability was met, as $20 \%$ of the observations were transcribed by 2 research assistants and they had to agree on the total number of words said.

Once the transcriptions were completed, the research assistants went back through the transcribed Microsoft Word documents to identify those words which qualified as spatial language words. The spatial language words were determined from the coding system developed by Cannon, Levine, and Huttenlocher (2007). These researchers developed this coding system to examine parents' usage of spatial language while engaged in puzzle play with their infants. In the current study, words from Cannon, Levine, and Huttenlocher's (2007) Part C. Location and Direction (pp. 12-14; a complete table of the words in Part C is located in Appendix B) of the coding system document were used as the spatial words to identify in the transcriptions. Examples of spatial prepositions from this list include, but are not limited to: from, in, out, under, above, and behind. When the transcription and identification of spatial language words were completed, and the total number of words and the total number of spatial prepositions said by the mother were recorded, analysis began.

The transcription team went through rigorous training to ensure that the spatial words being counted were being used in a spatial context, and not meaning its non-spatial definition. For example, the word "to" has non-spatial definitions, as well as homophones, "too" and "two." The researchers worked to carefully so that these words were not counted towards the number of spatial prepositions heard and said. While there is documented reliability of total word count, there is not documented reliability for spatial preposition count. 


\section{CHAPTER IV: RESULTS}

There were three research questions which were addressed in this study. The first two questions were: Do mothers use more spatial language with male children than female children? Second, do the number of spatial prepositions that mothers say to their infants increase over time depending on the gender of the infant? These questions were addressed using a repeated measures ANOVA.

This question was addressed in the methods by observing the frequency of spatial words used by each mother at each visit. As is common with longitudinal data (Ibrahim and Molenberghs, 2009), a certain amount of data was missing from the current data set. Across all the infants and time points, $11 \%$ of the data points were missing. The missing data may have been due to the fact that the families were not available to meet at the time of data collection. For this reason, the expectation maximization method for missing data was utilized. This method uses regression equations in SPSS to estimate the missing values (Schafer and Olsen, 1998). After SPSS completes the regression equations, a new data set is created that filled in the missing data, and analysis can begin with the updated data. By utilizing the expectation maximization method, it was possible to use the total sample of 37 mother/infant dyads in the repeated measures analysis.

A repeated measures ANOVA was conducted in which the independent variable of time

(6 play observations) and the dependent variable (frequency of spatial prepositions) were entered into the model along with sex of the infant as a between-subjects factor. The assumption of sphericity was not violated, as indicated by Mauchly's test, $x^{2}(14)=18.95, p=.168$. Because sphericity can be assumed, the tests of within-subjects effects reveal that the frequency of spatial 
words said does change over time, $F(5,170)=4.26, p=.001$. These results suggest that there was a change in the number of spatial words said by mothers across time.

Pairwise comparisons reveal that there is a significant differences between the number of spatial word said to infants at the baseline visit $(M=13.02, S D=8.52)$ compared to the 3-month follow-up $(M=17.99, S D=12.35 ; p=.03)$, the 6-month follow-up $(M=19.98, S D=9.23 ; p=$ $.000)$, and the 12-month follow-up $(M=20.95, S D=12.97 ; p=.001$; see Figures 1 and 2$)$. These comparisons illustrated that mothers increase the number of spatial prepositions that they say from the first observation to the final three observations.

There were also significant differences between the 3-week follow-up observation $(M=$ $14.51, S D=9.65)$ and the 6 -month observation $(M=19.98, S D=9.23 ; p=.051)$, and the $12-$ month observation $(M=20.95, S D=12.97 ; p=.017)$. Again, there was an increase in the frequency of spatial words said from the earlier observation to these later observations.

Finally, the 1.5 -month follow-up $(M=13.83, S D=7.82)$ differed significantly from the 6-month $(M=19.98, S D=9.23 ; p=.005)$ and 12-month follow-up visits $(M=20.95, S D=$ $12.97 ; p=.002$ ) with mothers saying significantly more words at the 6- and 12-month visits than at the 1.5 month visit.

The total average number of spatial words said to female participants was 15.27 (SEM= 1.76) and the total average number of spatial words said to male participants was 18.03 (SEM= $2.04)$, however this difference was not significant, $F(1,34)=1.32, p=.258$. Therefore, the hypothesis that mothers will say more spatial words to male children as compared to female children was not supported. Because there was not a group (sex) by time (observation) interaction effect, follow up post hoc effects for group across time were not examined. 
Due to the small frequency of the total number of times each prepositional word or phrase was said, analysis on specific words were not conducted. Figure 3 reflects the number of times each preposition was said across all visits and between both male and female children. As shown in Figure 3, "at," "to," and "in" $(M=11.95$ for female infants, $M=9.59$ for male infants; $M=23.55$ for female infants, $M=19.71$ for male infants; and $M=19.05$ for female infants, $M=$ 13.71 for male infants, respectively) were the prepositions that were said most often to male and female children in the block play scenarios.

Lastly, do mothers change the total words spoken to their infants across time and do they speak more words in total to male infants over female infants? This question was addressed using expectation maximization and a repeated measures ANOVA. The expectation maximization method was again employed to account for the $11 \%$ of missing data (Schafer and Olsen, 1998).

A repeated measures ANOVA was conducted in which the independent variable of time (6 play observations) and the dependent variable (amount of total words) were entered into the model along with sex of the infant as a between-subjects factor. The assumption of sphericity was not violated, as indicated by Mauchly's test, $x^{2}(14)=21.27, p=.096$. Because sphericity can be assumed, the tests of within-subjects effects reveal that the total number of words said does change over time, $F(5,170)=4.68, p=.001$. These results suggest that there was an increase in the number of total words said by mothers across time.

Pairwise comparisons reveal that there is a marginally significant difference between the number of total words said to infants at the baseline visit $(M=245.85, S D=141.23)$ compared to the 6-month follow-up $(M=302.32, S D=100.36 ; p=.056)$, and a significant difference between the baseline visit and the 12-month follow-up $(M=304.33, S D=105.68 ; p=.023$; see Figures 4 
and 5). This comparison illustrates that mothers increase the total number of words that they say from the first observation to the final two observations.

There was also a significant difference between the 3-week follow-up observation $(M=$ 257.48, $S D=124.88)$ and the 12-month observation $(M=304.33, S D=105.68 ; p=.038)$.

Again, there was an increase in the total number of words said from the earlier observation to the last observation.

The total average number of words said to female participants was $268.95(S E M=21.73)$ and the total average number of words said to male participants was $290.62(S E M=25.71)$, however this is not different enough to be considered a significant finding, $F(1,34)=.415, p=$ .524. Therefore, the hypothesis that mothers will say more total words to male children as compared to female children is not supported. Because there was not a group (sex) by time (observation) interaction effect, follow up post hoc effects for group across time were not examined. 


\section{CHAPTER V: DISCUSSION}

The present study sought to add to the existing literature of language acquisition by examining parent language during a play session which promotes the use of spatial words. The present study also extends the research of Marcinowski and Campbell (2017). Their study found that infants who show greater skill at construction have greater knowledge of spatial prepositions that infants who are less skilled at constructing objects. The mechanism by which this relation occurs is unknown. One factor that may be a mechanism by which infants learn spatial prepositions is by hearing parents use spatial prepositions when engaged in activities that promote the use of such words. To contribute to this knowledge of whether parents spatial preposition use has an influence on infant knowledge of spatial prepositions, this study examined the frequency with which parents utilize spatial prepositions and whether there is a difference in using spatial preposition by male and female infants. Total word use was also examined.

The analyses revealed that mothers do increase the number of spatial prepositions that they say to their infants across time, saying significantly more spatial prepositions at the 6- and 12month follow-ups as compared to earlier observations. Mothers said on average the same number of spatial prepositions to male and female infants.

The analyses also revealed that mothers do increase the total number of words that they say to their infants across time, saying significantly more words at the 12-month follow-up as compared to earlier observations. Mothers said on average the same number of total words to male and female infants.

The outcome of the present study are not in line with the outcomes of the research described above. This could be due to the small sample size; only 37 dyads participated, as compared to other studies discussed, who recruited upwards of 175 mother/child dyads (Christakis et al., 
2007). Another possible difference could be due to how data were collected. The present study utilized a longitudinal design, collecting data points for all participants across a calendar year. While this is similar to data collection tactics from Crowley et al. (2001) and Pruden and Levine (2017), who also employed a longitudinal design, the rest of the studies described utilized a cross-sectional design, only manipulating data from one lab or home meeting. Considering the present study manipulated data from 6 meetings in total, if only one play scenario datum was manipulated, perhaps a different outcome would have resulted.

\section{Limitations}

One limitation of the study was the use of secondary data. There were instances where the coding team could not hear some statements in some videos, technology issues in getting access to the videos, and not having the ability to add to the data set. This last statement goes hand in hand with the limitation of the sample size. There was a total of 37 dyads that participated, which is an extremely small data set, especially compared to the previously described studies that recruited upwards of 175 (Christakis et al., 2007) mother/child dyads. This reduces the ability to generalize the results of these analyses. From that, the mothers' demographic information, while representative of the area they were recruited from, may not be representative of the population at large. Recall that a majority (59.5\%) of the mothers reported a household income exceeding $\$ 80,000$ per year and a majority $(62.2 \%)$ reported receiving a postgraduate degree, meaning a masters or a $\mathrm{PhD}$. Along with the mother's demographic information, it was so that only mothers were included in these play scenarios, not fathers. There may have been a different outcome if fathers were included in the analyses. While reliability was met with two research assistants transcribing $20 \%$ of the play scenarios, there were not reliability measures specifically taken in terms of the spatial word count. I am confident in 
myself and the research assistants, but future studies in this subject should emphasize more stringent reliability measures. A last limitation is the short time span the data were collected. While the data were collected over the span of a year, the infants would have been no older than 18 months at the time of the final play scenario. Perhaps their fine motor skills that would aid in putting the blocks together have not fully developed yet. If this is the case, I predict more spatial language would be said by the mothers as the infant's play abilities increased.

\section{Future Directions}

Future research using the same data set may look further into the type of toy used. The initial Marcinowski and Campbell (2017) research includes many different types of toy; the present study only focused on the colorful blocks that allow for small animals to be placed inside. Perhaps a different frequency of language more broadly, or prepositional words more specifically, would yield a larger discrepancy between male and female infants. Along with different toy types, future researchers could analyze a different part of speech, such as verbs, to determine if there is a difference in frequency with other types of words. As stated above, I predict more spatial language would be said by mothers as the infant's play abilities increased. It would be interesting to see how these co-vary with the language directed at the infants. The videos used for data analysis are available for this sort of study to occur. Lastly, I would suggest recruiting a larger and more diverse sample size, as the present sample size is small and not representative beyond the area the research was conducted. In conclusion, the examination of the factors that contribute to the simultaneous development of construction during play and language is important research in infant psychology. 


\section{REFERENCES}

Borriello, G. A., \& Liben, L. S. (2018). Encouraging maternal guidance of preschoolers' spatial thinking during block play. Child Development, 49(4), 1209-1222. doi: 10.1111/cdev.12779

Cannon, J., Levine, S., \& Huttenlocher, J. (2007). A system for analyzing children and caregivers' language about space in structured and unstructured contexts. Spatial Intelligence and Learning Center (SILC) technical report.

Casasola, M., \& Wilbourn, M. P. (2004). 14-month-old infants form novel word-spatial relation associations. Infancy, 6(3), 385-396.

Christakis, D. A., Zimmerman, F. J., \& Garrison, M. M. (2007). Effect of block play on language acquisition and attention in toddlers. Archives of Pediatrics and Adolescent Medicine, 161(10), 967-971.

Clearfield, M. W., \& Nelson, N. M. (2006). Sex differences in mothers' speech and play behavior with 6-, 9-, and 14-month-old infants. Sex Roles. 54(1). 127-137. doi: $10.1007 /$ s1 1199-005-8874-1

Crowley, K., Callanan, M. A., Tenenbaum, H. R., \& Allen, E. (2001). Parents explain more often to boys than to girls during shared scientific thinking. Psychological Science. 12(3). 258261.

Ferrara, K., Hirsh-Pasek, K., Newcombe, N. S., Golinkkoff, R. M., \& Lam, W. S. (2011). Block talk: Spatial language during block play. International Mind, Brain, and Education Society. 5(3). 143-151. 
Greenfield, P. M. (1991). Language, tools and brain: The ontogeny and phylogeny of hierarchically organized sequential behavior. Behavioral and Brain Sciences. 14. 531595.

Ibrahim, J. G., \& Molenberghs, G. (2009). Missing data methods in longitudinal studies: A review. Test, 18(1), 1-43.

Kaushanskaya, M., Gross, M., \& Buac, M. (2013). Gender differences in child word learning. Learning and Individual Differences. 27. 82-89. doi: 10.1016/j.lindif.2013.07.002

Marcinowski, E. C., \& Campbell, J. M. (2017). Building on what you have learned: Object construction skill during infancy predicts the comprehension of spatial relations words. International Journal of Behavioral Development. 41(3). 341-349. doi: $10.1177 / 0165025416635283$

Meints, K., Plunkett, K., Harris, P. L., \& Dimmock, D. (2002). What is 'on' and 'under' for 15-, 18- and 24-month-olds? Typicality effects in early comprehension of spatial prepositions. British Journal of Developmental Psychology, 20. 113-130.

Pruden, S. M., \& Levine, S. C. (2017). Parents' spatial language mediates a sex difference in preschoolers' spatial-language use. Psychological Science. 28(11). 1583-1596. doi: $10.1177 / 0956797617711968$

Schafer, J. L. \& Olsen, M. K. (1998). Multiple imputation for multivariate missing-data problems: A data analyst's perspective. Multivariate Behavioral Research, 33, 545-571.

Ullman, M. T., Estabrooke, I. V., Steinhauer, K., Brovetto, C., Pancheva, R., \& Ozawa, K. (2002). Sex differences in the neurocognition of language. Brain and Language. 83. 141143. 


\section{APPENDIX A: PHOTOGRAPH OF BLOCKS USED}

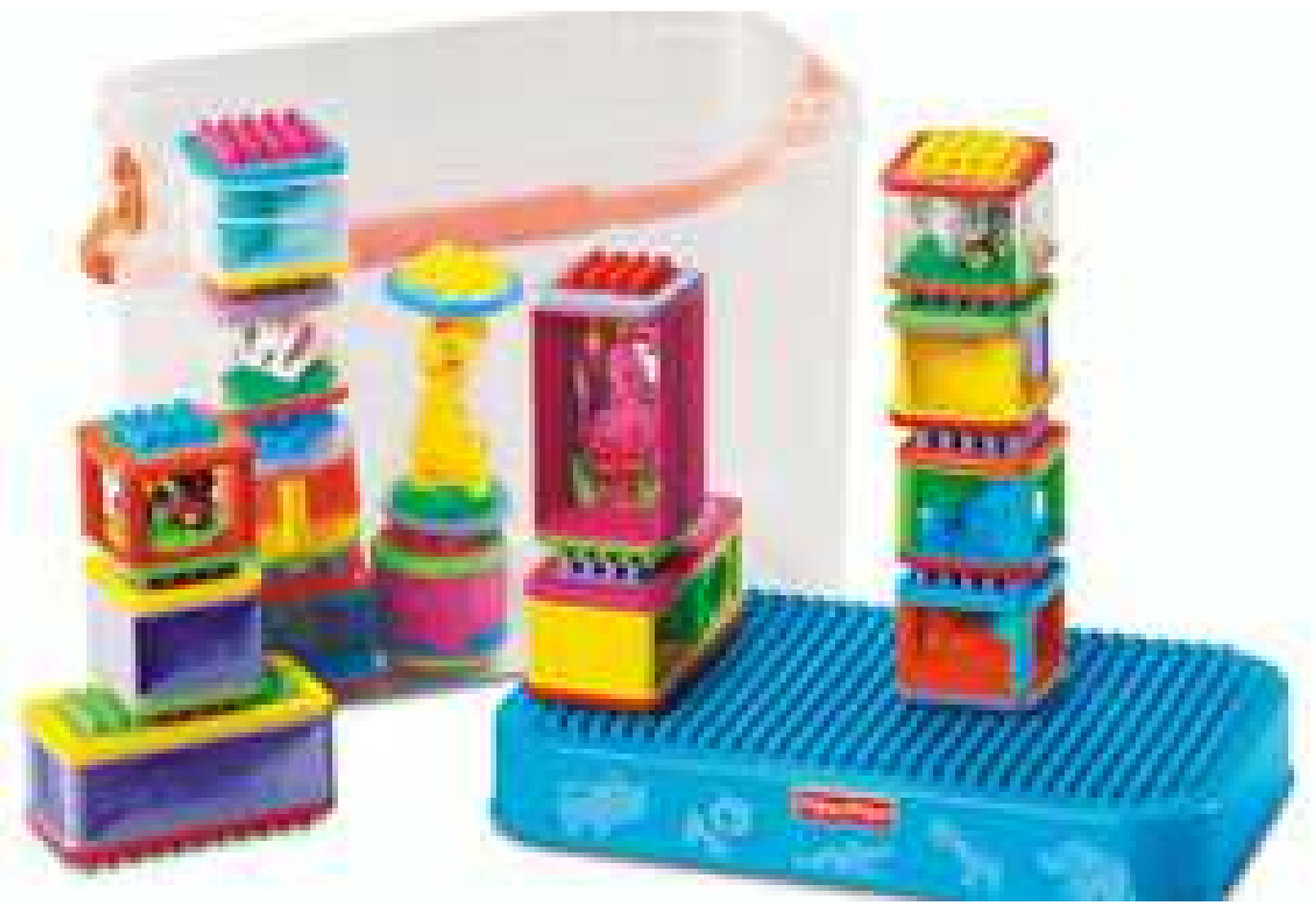


APPENDIX B: COMPLETE TABLE OF SPATIAL WORDS USED FOR CODING

\begin{tabular}{|c|c|c|}
\hline $\begin{array}{l}\text { Concept } \\
\text { Terms that refer to a position } \\
\text { (or movement towards a position) } \\
\text { that is: }\end{array}$ & Words & $\begin{array}{l}\text { Additional } \\
\text { forms }\end{array}$ \\
\hline $\begin{array}{l}\text { the noun that follows the term } \\
\text { (in the case of "from" the reference is to } \\
\text { movement away from the noun) }\end{array}$ & $\begin{array}{l}\text { At } \\
\text { To } \\
\text { From }\end{array}$ & -ward(s) \\
\hline $\begin{array}{l}\text { resting/ not resting along a surface } \\
\text { (including an "invisible" surface that is a } \\
\text { boundary of a space such as in "on the } \\
\text { side" and "on the bottom") }\end{array}$ & $\begin{array}{l}\text { On } \\
\text { Off }\end{array}$ & -to, up- \\
\hline $\begin{array}{l}\text { within or outside of the boundaries of an } \\
\text { area or confines of a volume }\end{array}$ & $\begin{array}{l}\text { In } \\
\text { Out (of) }\end{array}$ & $\begin{array}{l}\text {-to, -side, with- } \\
\text {-side }\end{array}$ \\
\hline $\begin{array}{l}\text { along a vertical axis } \\
\text { (in the case of "top" and "bottom" this } \\
\text { includes the intrinsic vertical axis of the } \\
\text { object/ person) }\end{array}$ & $\begin{array}{l}\text { Under } \\
\text { Beneath } \\
\text { Below } \\
\text { Over } \\
\text { Above } \\
\text { Up } \\
\text { Down } \\
\text { (On) top } \\
\text { Bottom } \\
\text { High } \\
\text { Low } \\
\text { Column } \\
\text { Vertical }\end{array}$ & $\begin{array}{l}\text {-neath } \\
\text {-er, -ward } \\
\text {-er, -ward } \\
\text {-er, -est } \\
\text {-er, -est } \\
\text {-s } \\
\text {-ly }\end{array}$ \\
\hline $\begin{array}{l}\text { along a horizontal axis } \\
\text { (in the case of "front", "back", "left", and } \\
\text { "right" this includes the intrinsic } \\
\text { horizontal axis of the object/ person) }\end{array}$ & $\begin{array}{l}\text { Left } \\
\text { Right } \\
\text { (In) front } \\
\text { (In) back } \\
\text { Ahead } \\
\text { Behind } \\
\text { Sideways } \\
\text { Row } \\
\text { Horizontal }\end{array}$ & $\begin{array}{l}\text {-ward } \\
\text {-ward }\end{array}$ \\
\hline
\end{tabular}




\begin{tabular}{|c|c|c|}
\hline $\begin{array}{l}\text { Concept } \\
\text { Terms that refer to a position } \\
\text { (or movement towards a position) } \\
\text { that is: }\end{array}$ & Words & $\begin{array}{l}\text { Additional } \\
\text { forms }\end{array}$ \\
\hline proximal/ distal to another point & $\begin{array}{l}\text { By } \\
\text { Near } \\
\text { Close } \\
\text { Next to } \\
\text { With } \\
\text { Beside } \\
\text { Far } \\
\text { Away } \\
\text { Beyond } \\
\text { Further } \\
\text { Past } \\
\text { Against } \\
\text { Together } \\
\text { Separate } \\
\text { Join } \\
\text { Apart }\end{array}$ & $\begin{array}{l}\text {-by, -er, -est } \\
\text {-er, -est } \\
\text {-er, -est }\end{array}$ \\
\hline $\begin{array}{l}\text { defined with respect to the location of at } \\
\text { least two other object/ people/ points }\end{array}$ & $\begin{array}{l}\text { Between } \\
\text { Among }\end{array}$ & \\
\hline $\begin{array}{l}\text { an equal distance from the extremities of } \\
\text { something }\end{array}$ & $\begin{array}{l}\text { Middle } \\
\text { Center }\end{array}$ & \\
\hline in the broad vicinity of another point & $\begin{array}{l}\text { About } \\
\text { Around } \\
\text { Throughout }\end{array}$ & \\
\hline $\begin{array}{l}\text { defined with respect to the length of an } \\
\text { object/ person/ point }\end{array}$ & $\begin{array}{l}\text { Along } \\
\text { Lengthwise }\end{array}$ & \\
\hline in a cardinal direction & $\begin{array}{l}\text { North } \\
\text { South } \\
\text { East } \\
\text { West }\end{array}$ & $\begin{array}{l}\text {-ern } \\
\text {-ern } \\
\text {-ern } \\
\text {-ern }\end{array}$ \\
\hline $\begin{array}{l}\text { from one side to another side of (or } \\
\text { circumvents) another object/ person/ } \\
\text { point }\end{array}$ & $\begin{array}{l}\text { Around } \\
\text { Through }\end{array}$ & \\
\hline $\begin{array}{l}\text { on the (other) side of another object/ } \\
\text { person/ point }\end{array}$ & $\begin{array}{l}\text { Across } \\
\text { Over } \\
\text { Opposite } \\
\text { Aside } \\
\text { Reverse }\end{array}$ & \\
\hline
\end{tabular}




\section{FIGURES}

Figure 1

Average Number of Spatial Prepositions Said Across Visit, Regardless of Sex of Infant

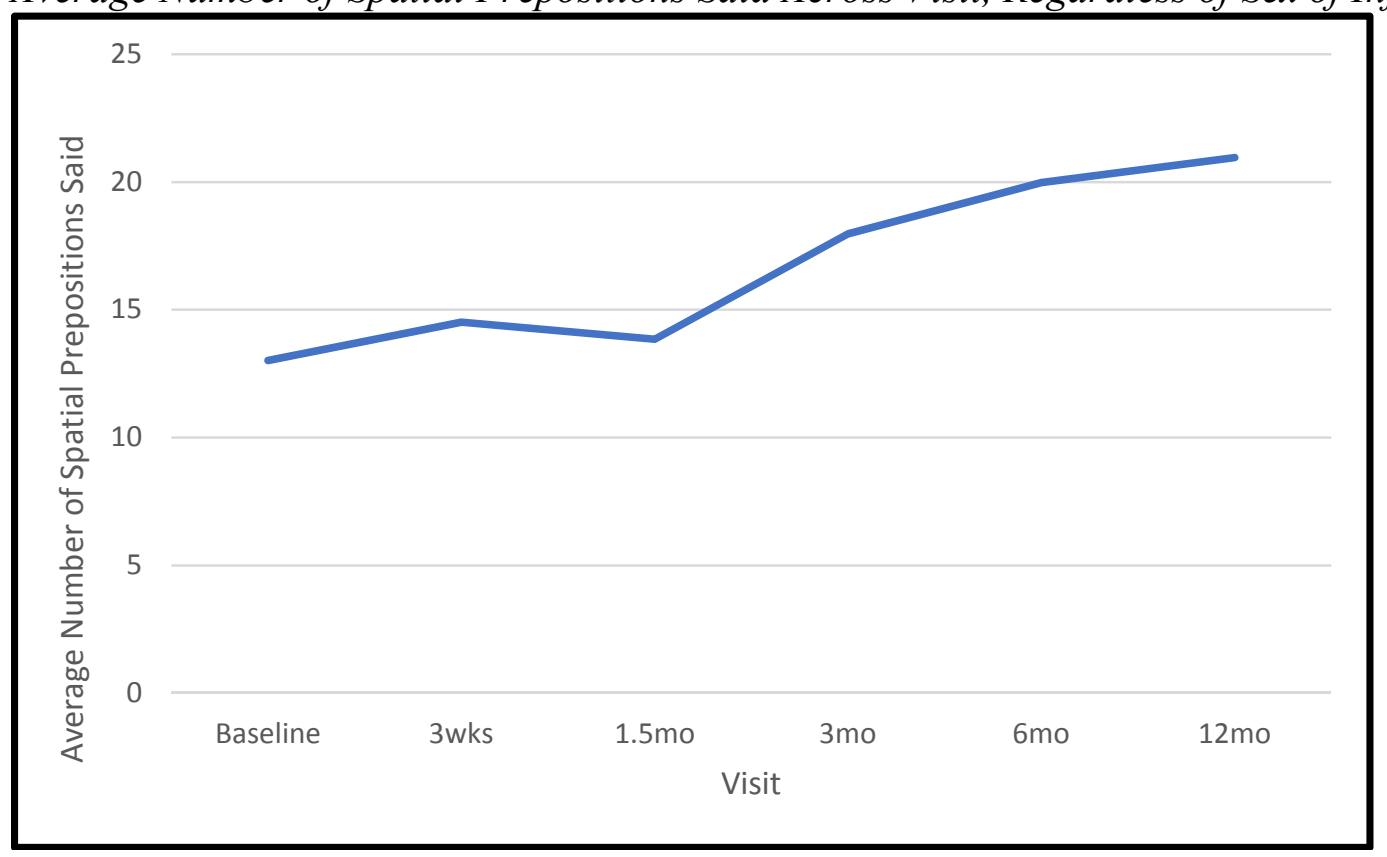




\section{Figure 2}

Average Number of Spatial Prepositions Said Across Visit, In Regards to Sex of the Infant

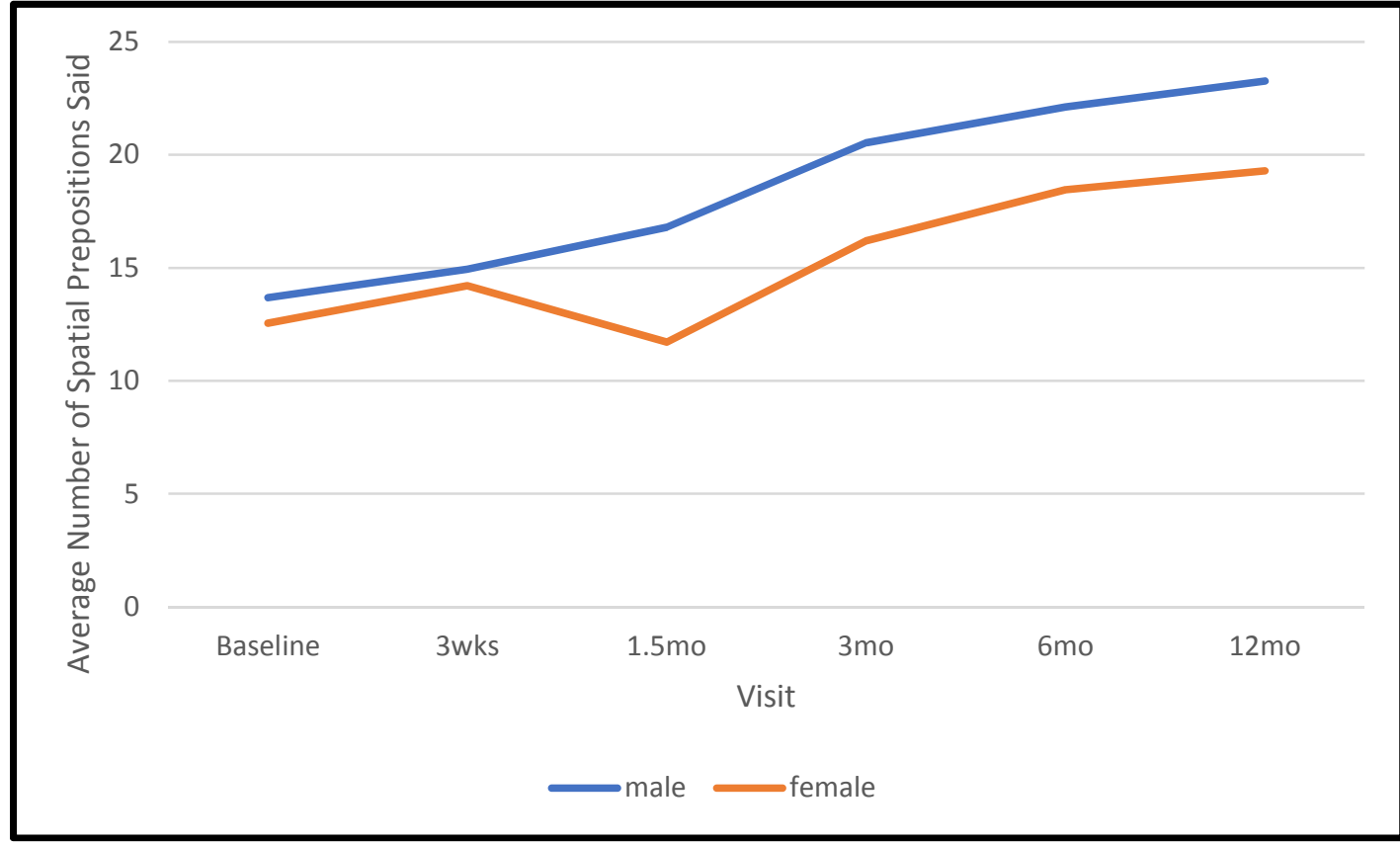




\section{Figure 3}

Number of Times the Spatial Preposition was Said by the Mother, in Regards to Sex

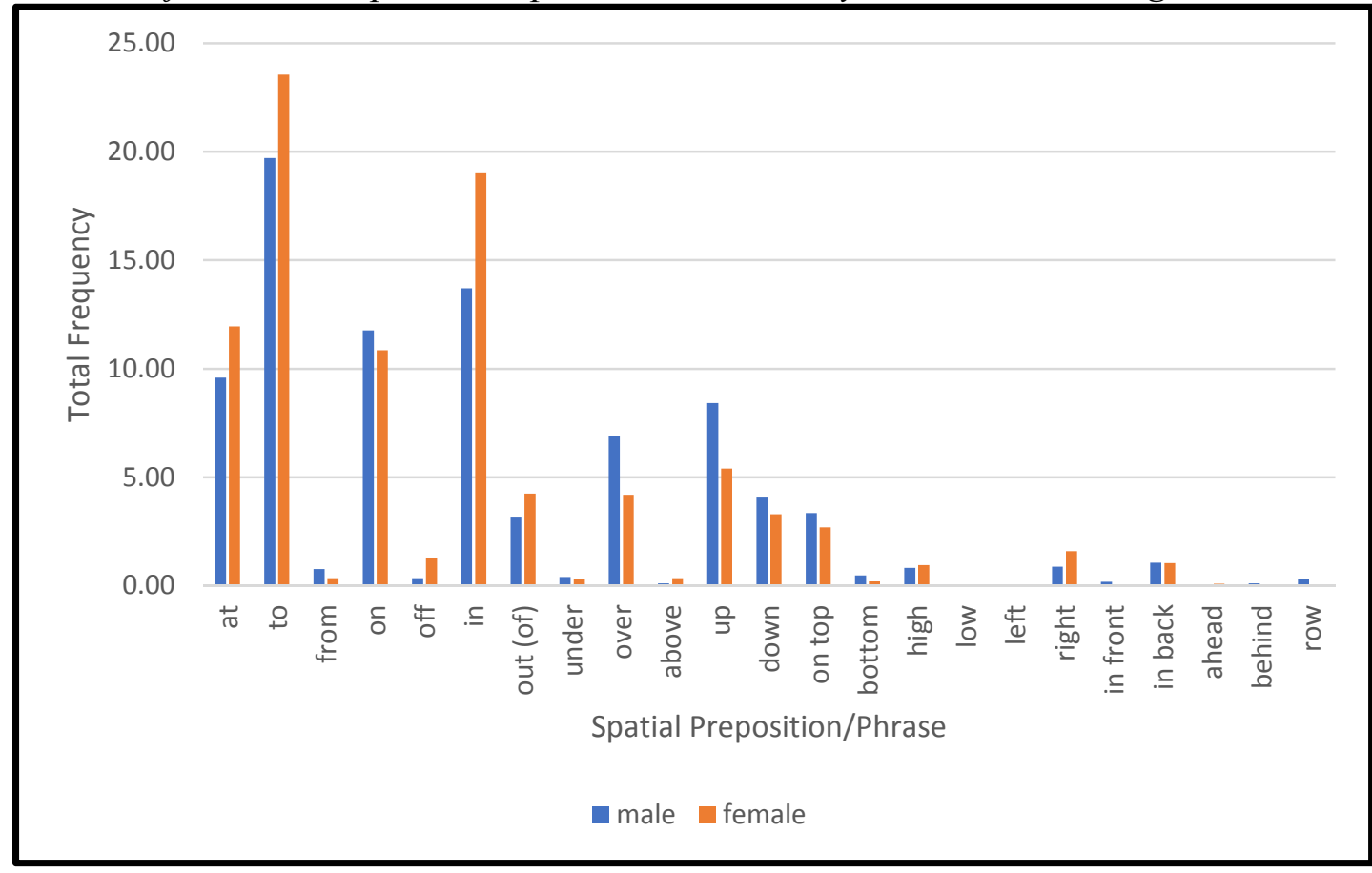


Figure 4

Average Number of Total Words Said Across Visit, Regardless of Sex of Infant

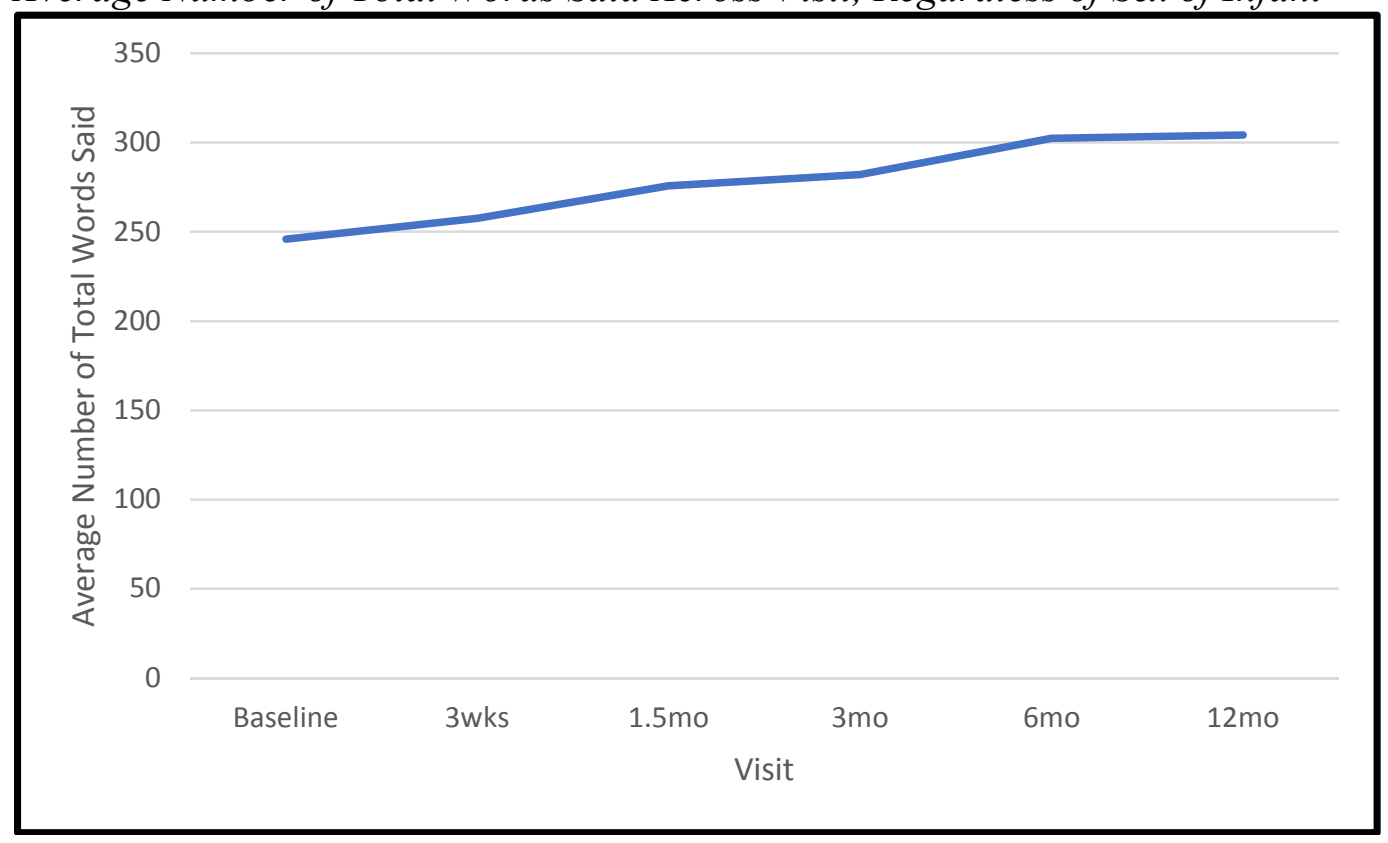




\section{Figure 5}

Average Number of Total Words Said Across Time, In Regards to Sex of Infant

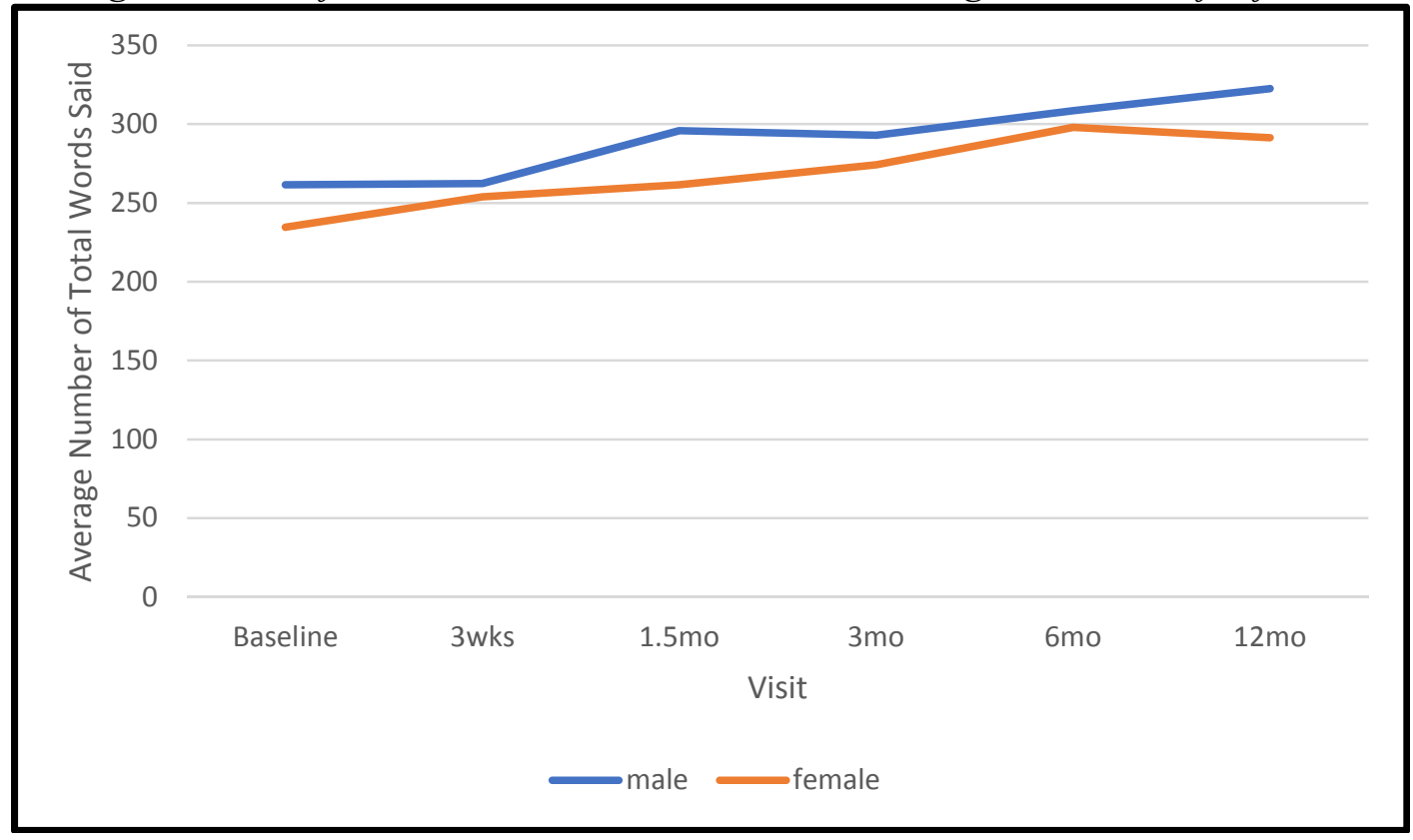

